\title{
Predicting soil depth to bedrock in an anthropogenic landscape: a case study of Phewa Watershed in Panchase region of Central-Western Hills, Nepal
}

\author{
*Sanjaya Devkota ${ }^{1}$, Narendra Man Shakya ${ }^{1}$, Karen Sudmeier ${ }^{2}$, Brian G. McAdoo ${ }^{3}$, and Michel Jaboyedoff ${ }^{2}$ \\ ${ }^{1}$ Department of Civil Engineering, Institute of Engineering, Tribhuvan University, Nepal \\ ${ }^{2}$ Institute of Earth Science, University of Lausanne, Lausanne, Switzerland \\ ${ }^{3}$ Yale-NUS College, Singapore \\ *Corresponding author: devkotasanjaya@gmail.com
}

\begin{abstract}
The Soil Depth to Bedrock (SDtB) parameter is highly variable over the landscape and is an important input for soil surface modeling including various types of mass movement that most often ignores the variability of soil depth. In landscapes that have been heavily modified by humans, SDtB parameters do not necessarily depend on natural processes, making it difficult to apply physically-based approaches. This study explored the possibility of using topographic attributes to model the SDtB in the complex topography of Phewa watershed in the Panchase region of Nepal. In June 2017, 865 SDtB points were surveyed along the excavated rural roads (approximately $300 \mathrm{~km}$ ) within the watershed $\left(111 \mathrm{~km}^{2}\right)$. Topographic attributes such as slope, curvatures, altitude and compound terrain index were derived from a Digital Terrain Model along with Land use land cover attributes derived from recent Landsat remote sensing images. Utilizing these attributes as explanatory variables, we implemented simple kriging (SK) and multiple linear regressions (MLR) to predict SDtB for the watershed. The results showed that the MLR predicted SDtB map was statistically significant $\left(\mathrm{R}^{2}=68 \%, \mathrm{EC}=\right.$ $0.93)$ over the SK $\left(\mathrm{R}^{2}=12 \%, \mathrm{EC}=-0.46\right)$. We concluded that the MLR approach in predicting SDtB for the complex geo-morphologic landscape such as the Phewa watershed in the Panchase region of Nepal can effectively be used, helping to inform the evolution of land-use as the region continues to develop.
\end{abstract}

Keywords: Anthropogenic landscape, Soil depth to bedrock, Soil surface modeling

Paper Received: 31 Jan 2018

Paper Accepted: 8 March 2018

\section{INTRODUCTION}

Soil Depth to Bedrock (SDtB), also known as regolith thickness, is important parameter to understand critical factors that affect the development of mountainous regions such as slope stability, surface erosion, ground water storage, vegetation growth, etc, however this soil thickness is highly variable over space (Kuriakose et al., 2009; Tesfa et al., 2009; Michel, 2016). Despite the importance of soil depth, most studies have used constant soil depth, ignoring the spatial variability (Kuriakose et al., 2009). The reason for adopting the constant soil depth is to measure every point in the field. The constant soil depth model is convenient in terms of reliable data generations. However, rigorous slope stability, vegetation growth and ground water availability assessment require more accurate soil depth data.

Soil scientists and engineers consistently explore the possibility of obtaining reliable SDtB utilizing data on soil formation processes and terrain attributes (e. g. Moore et al., 1991; Tsai et al., 2001; Kuriakose et al., 2009; Tesfa et al., 2009; Michel, 2016). Physical methods consider soil formation processes to estimate the SDtB utilizing the rate of bedrock degradation, denudation and accumulation, and physical properties of regolith materials or underlying rock (Kuriakose et al. 2009). Dietrich et al. (1995) proposed spatio-temporal prediction of colluvial soil depth based on the mass balance between soil production from underlying bedrock and soil transport erosion. The mass balance method was successfully validated in a sub-catchment in United States. Several other studies have also proposed similar methods to predict soil depth.

In order to have continuous SDtB maps, the soil depth measured at several points can be interpolated to estimate the depth in between. The common interpolation techniques are geostatistical (e. g. kriging) or non-geostatistical (e. g. Thiessen polygon, inverse-distance, etc). Non-geostatistical techniques do not consider any randomness of the data field and thus they do not provide prediction variances, whereas geostatistical approaches use the spatial autocorrelation of a phenomenon based on the theory of random fields to interpolate over the area (Goovaerts, 1997; Kuriakose et al., 2009). Moore et al. (1993) followed by Gessler et al. (1995) adopted statistical techniques to model the pattern of soil properties over landscapes. Relationships between soil properties and landscape factors (e.g., slope, wetness index, and plan curvature) were extracted from point measurements and then used to predict soil properties over the remaining area. Geostatistical approaches in other hand 
have also been used to interpolate soil properties (Kuriakose et al., 2009; ZIADAT, 2010) but their application is often limited by the large amount of data required to define the spatial autocorrelation (Tesfa et al., 2009).

McBratney and Odeh (1997) suggested fuzzy logic, a logic that attempts to solve problems by assigning values to an imprecise spectrum of data, to arrive at the most accurate possible conclusion as an approach to refine the scale of soil information. Zhu and Band (1994) and Zhu et al. (1996, 1997) developed a model (e. g. SoLIM) that combines fuzzy logic with GIS and expert system development techniques that capture the opinions of experts in the fuzzy logic functions used to map soil attributes from spatial soil forming factors. Zhu and Mackay (2001) took this approach a step forward and evaluated the effects of spatial detail of soil information, generated by SoLIM model at the watershed scale to demonstrate that the detailed spatial soil information influenced simulated hydrographs indicating the importance of detailed spatial soil information for hydro-ecological modeling (Tesfa et al., 2009).

In comparison to the above statistical techniques, Dietrich et al. (1995) suggested a process-based approach for predicting the spatial variation of colluvial soil depth, assuming that (a) soil production is a function of soil depth, (b) soil transport is proportional to slope and (c) soil production is in local dynamic equilibrium with the divergence of soil transport. Topographic curvature becomes a surrogate for soil production (Tesfa et al., 2009). The concept of soil production, transportation and terrain slope was adopted by various researchers (Heimsath et al., 2000; Heimsath and Ehlers, 2005; Saco et al., 2006) who demonstrated that soil depth could vary spatially under the dynamic equilibrium (Tesfa et al., 2009). However, the cause of soil production and its impact on soil moisture, vegetation growth, and slope stability have only had limited evaluation (Tesfa et al., 2009). In addition, the role of chemical and physical breakdown of the underlying rock, its influence on soil production and soil depth, and the effect on various topographic attributes such as aspect, slope, elevation, curvature etc. were not explicitly considered in the above discussed statistical and physical models.

The modeling approaches discussed above for predicting soil depth over landscapes, indicated partial success (Tesfa et al., 2009). While the physically based model demonstrated by Dietrich et al. (1995) has shown reasonable prediction capability in unchanneled valleys (Tesfa et al., 2009), obtaining reliable data and information for modeling SDtB through the physical process method remains difficult, complex, time and cost driven. For this reason, simple and efficient methods to estimate SDtB is essential for many lower income countries like Nepal, where soil erosion and mass wasting process are frequent and have great impact on livelihoods and the environment (SudmeierRieux et al., 2012) .

In this paper, we compared a simple geostatistical (i. e. simple kriging) and non-geostatistical (i. e. multiple linear regression) techniques to predict spatial pattern of SDtB in the topographically complex terrain in the Phewa watershed, utilizing topographic and land cover attributes as explanatory and soil depth as response variable. We introduce topographic attributes of the Phewa watershed derived from a $20 \mathrm{~m}$ resolution digital elevation model (DEM), and anticipated to have explanatory capability for soil depth. The land cover attributes were derived partially from Landsat and Rapid-Eye remote sensing images of June 2015 and May 2014, respectively.

The Phewa watershed in the Panchase region is complex in terms of topography and environment, where landslides are frequently occurring hazards, damaging the livelihood and environment. In addition, the region is under pressure of anthropogenic activities such as unplanned rural road construction leading more landslides during the monsoon season (Jaboyedoff et al., 2016; Leibundgut et al., 2016). For better understanding the fragile landscape of the Phewa watershed and to implement effective landslide mitigation measures, reliable soil depth data is important. The unplanned rural roads in the watershed facilitated to obtain $865 \mathrm{SDtB}$ points, the points used to predicted soil depth. Two different techniques (i. e. simple kriging and multiple linear regression) discussed above were implemented to predict the SDtB at the watershed scale.

\section{STUDY AREA}

This study was carried out in the Phewa Lake watershed in the Central-Western Hills of Nepal (Fig. 1). The area is commonly known as the Panchase region. It is popular due to its biodiversity and tourism but is also prone to natural hazards such as landslides, soil erosion and flash floods. The watershed consists of high internal relief, steep slopes, terraces made for cultivation, diverse forest resources and wildlife. The watershed is known to be complex in terms of topography, biodiversity and environment. Several small to medium type rain-fed streams originate in the hills and feed the Phewa Lake. The estimated area of the Phewa Lake watershed is approximately $111 \mathrm{sq} . \mathrm{km}$ where elevation varies from 792 meters above sea level (masl) at the lake outlet to 2,483 masl at the highest point known as Panchase peak. The sub-tropical climate region experiences intense monsoonal rainfall (June-Sept) and dry winters (DecMarch). The region is also known as for the highest rainfall area in the country. The recorded highest annual and daily rainfall in the region was about $5,500 \mathrm{~mm}$ and $315 \mathrm{~mm}$, respectively with the annual mean of 4,500 $\mathrm{mm}$ (Devkota and Adhikari, 2014). Stream flow typically remains low in the winter and is highest during the summer monsoon season.

The subtropical climate dominated vegetation in the watershed was observed in the lower elevations followed by temperate forest and grass land in the higher elevation. Soil in the area was basically fromed by weathering of the underlying parent material (e. g. phylites and quartzite). The soil ranges from silty-loam to loamy-sand. However significant amounts (15-20\%) of gravel are also found in the upper valley reach of the streams. The soils in the area are generally well drained and have high surface erosion potential leading to gullies thereby 


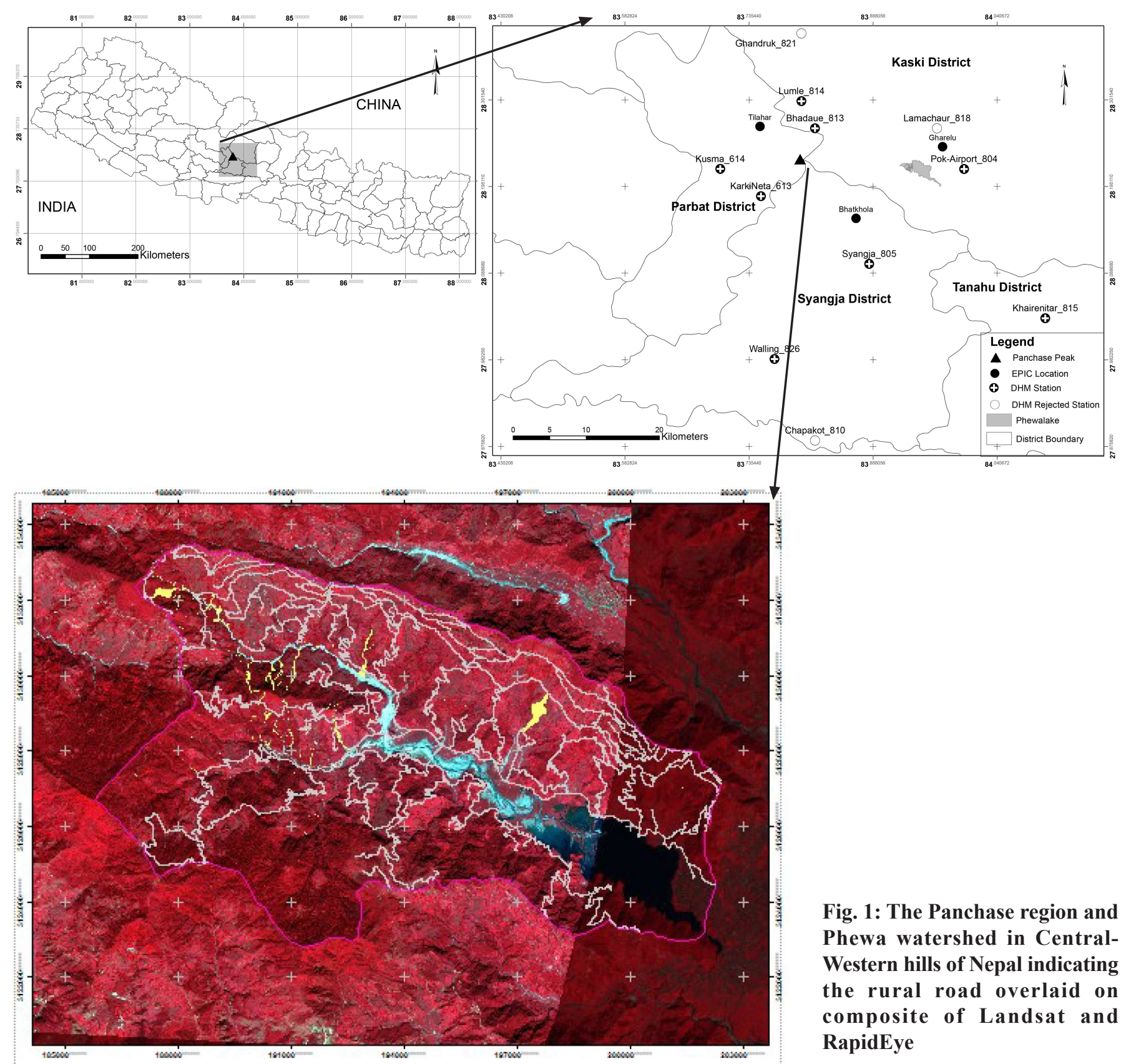

landslides. South facing slopes generally contain coarser texture than soils in the north facing slopes. South facing slopes have more rock outcrops than the north facing slopes.

Human intervention such as rural road construction, terraces for cultivation, new settlements, etc. in the watershed was observed to be very high. More recently people have migrated towards the valley side seeking better livelihoods, leaving the terraces unmaintained. According to Leibundgut et al., (2016), there were $315 \mathrm{~km}$ of rural roads within $111 \mathrm{~km}^{2}$ of the Phewa Lake watershed. This gives a total road density of about $2.7 \mathrm{~km} / \mathrm{km}^{2}$, which is exceptionally high for Nepal. Rural road construction continues as community people and government authorities keep excavating new roads in the fragile hills of the Panchase region.

\section{METHODOLOGY}

For better estimation of soil depth at the un-sampled locations in the Phewa watershed in the Panchase region, the heavily excavated rural roads were used to measure SDtB wherever bedrock was exposed either in the road surface or in the hill side slopes of the roads. Besides the road cut slopes, other points such as rock exposed on the natural surface and cultivated land were also captured. To develop reasonably precise soil depth data/map of the watershed, two simple techniques: (i) Simple Kriging (SK) and (ii) Multiple Linear 

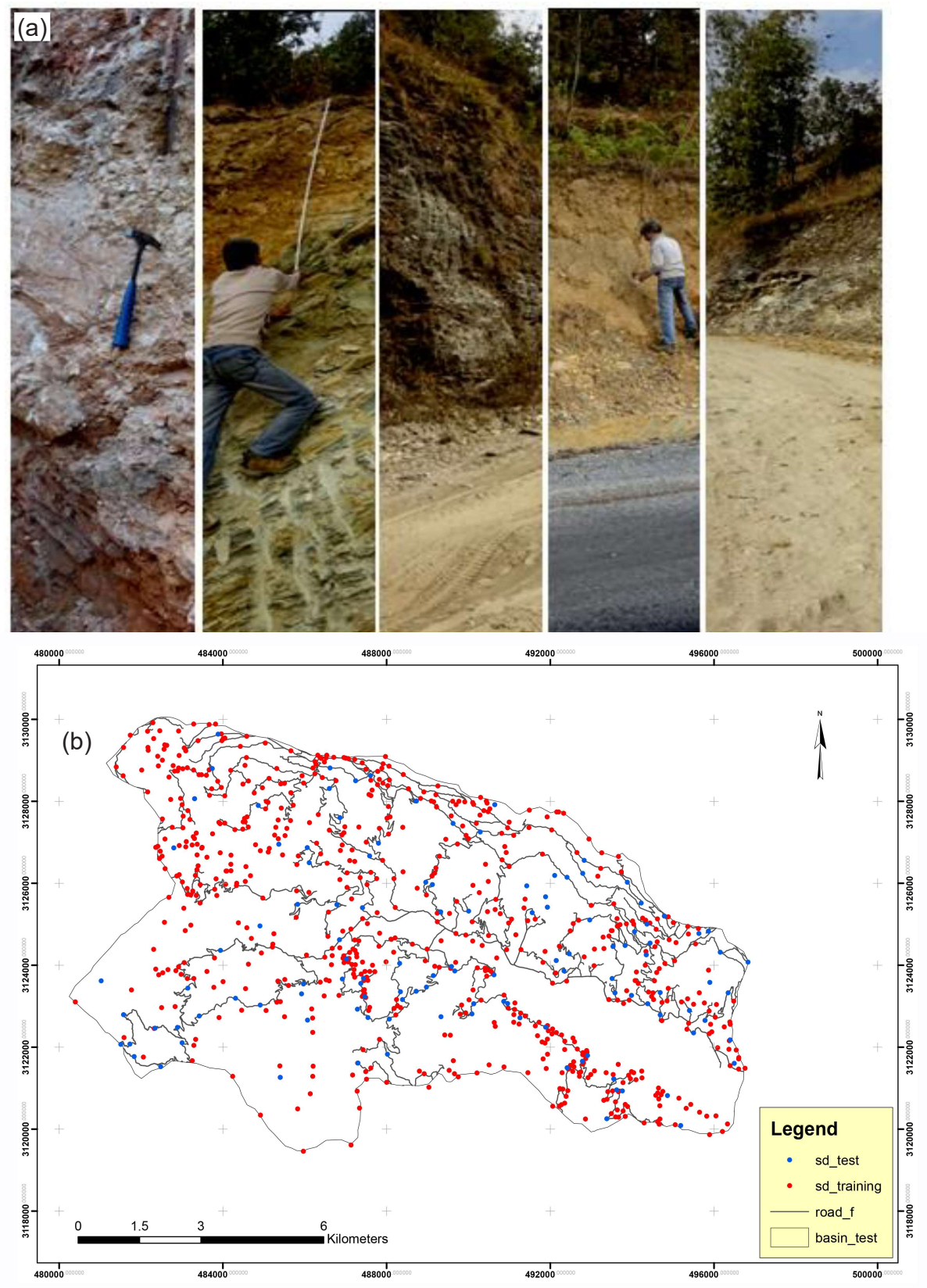

Fig. 2: (a) view of soil profile and measurement of SDtB and (b) the Phewa watershed and locations of SDtB points measured along the rural roads

Regression (MLR) utilizing the field measured SDtB point data bases were proposed.

\section{Field Data Collection}

The SDtB point measurements were carried out along the rural roads in the Phewa watershed. A GPS (3-4 meter accuracy), topographic map (1:25,000), 5 meter resolution RS images (Rapid-Eye) available from the University of Lausanne and aerial photographs of 1978 and 1996 available from Department of Survey of the Government (DoS) of Nepal were used to better understand the watershed.
Leigbundgut et al. (2016) was considered to understand the watershed in terms of land use changes, landslides, settlement and rural road construction. The GPS was set to route tracking mode as we walked along the roads, whenever the bedrock was observed. We measured its depth and marked using the GPS point. During the measurement, the surroundings were observed and a visual assessment of the topographic curvature (-1 for concave, 1 for convex and 0 for intermediate) of the recorded point was maintained. Furthermore, the dominant land cover type (dense forest, degraded forest, grass land, crop land, road, rock out crops, etc) was recorded. The advantage of this method was that there was no need of excavation or use of any knocking techniques as used in Kuriakose et al. (2009) and Tesfa et al. 


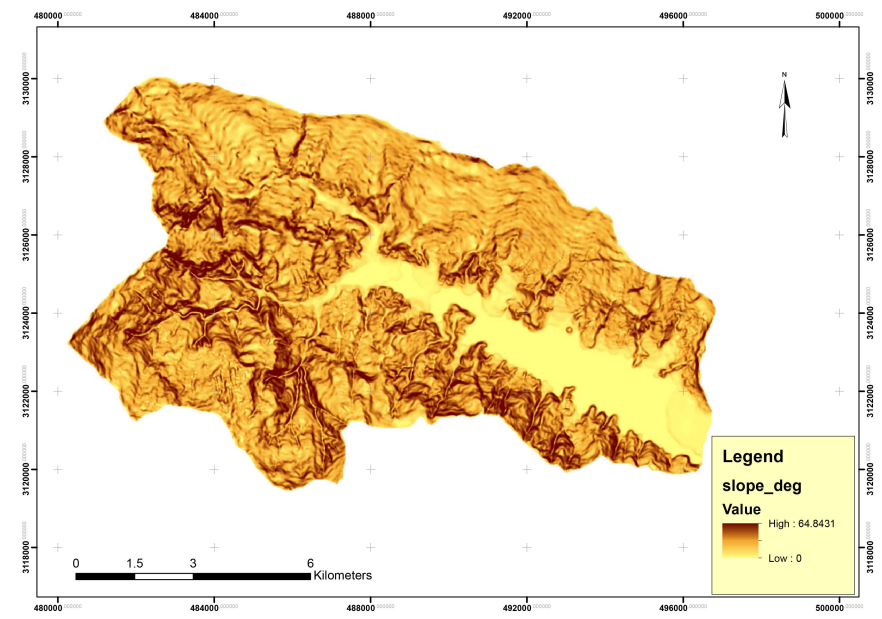

Fig. 3: Slope map (in degree) of Phewa watershed

(2009) or any use of geophysical methods. Since the rural roads in the watershed were built without proper assessment, this would result in unnecessary excavation, and lead to greater bedrock exposure at the road formation level or on the hillside slope of the road. The survey was carried out in the months of June 2017 during early monsoon, which also enabled us to map the status of the landslides before the beginning of the monsoonal rain season. In total, $795 \mathrm{SDtB}$ points were examined along the rural roads, 42 points were measured in the cultivated terraces and 18 points were the proxies where the bedrock was exposed on the surface (Fig. 2).

\section{Geo-spatial Data}

The digital topographic map of the region was obtained from the Department of Survey (DoS) of the Government of Nepal. The topographic map contains $20 \mathrm{~m}$ interval contours and several other layers such as settlement, streams, lake, Land use, etc. Utilizing the 20 meter contour map, we generated a DEM of the area (20 meter resolution). To ensure hydraulic connectivity within the watershed, the DEM was processed to remove elevation anomalies (e.g. sinks and peaks) that can interfere with hydrologically correct flow. In addition, null (NODATA) cells were filled using focal function (e.g. 'focal majority'). Various topographic attributes such as slope, flow direction, flow accumulation, aspect, compound terrain index (CTI), etc were derived from the DEM. In present study however, we derived slope, plan and profile curvatures and compound terrain index as explanatory variables because these are the variables that explain the SDtB as demonstrated in Tesfa (2009) and Devkota et al. (2008).

\section{Slope}

Slope can be derived from DEM by utilizing available GIS tools (i.e., 3 D analysis) (Fig. 3). Slope in general represents the change in elevation of any two points divided by the lateral distance. The general understanding of the slope and soil thickness on the terrain was that the erosive power increased
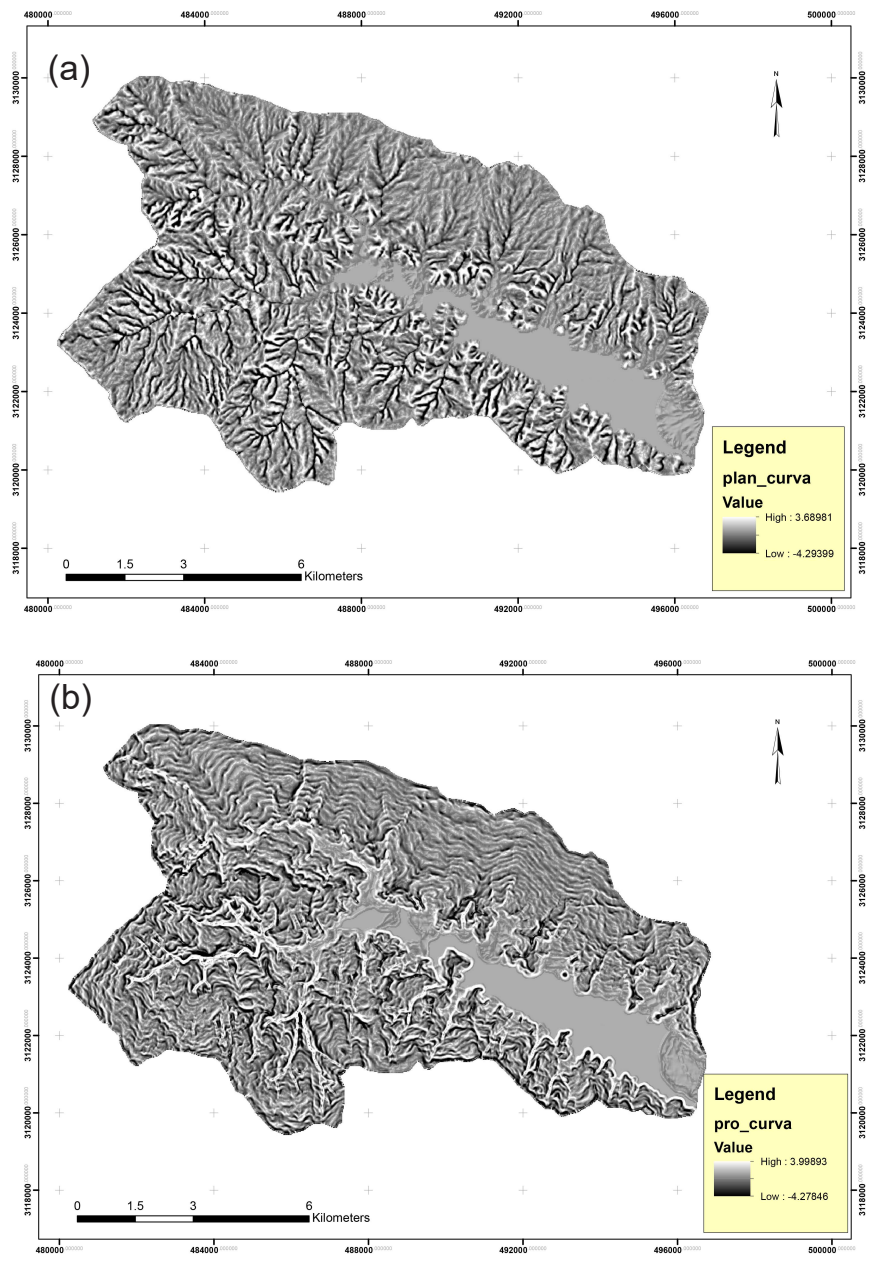

Fig. 4: (a) Plan and (b) profile curvature

on steeper slopes; we considered a linear inverse relationship between slopes and soil thickness. According to Tesfa et al. (2009) the relative position of a point on a hillslope can be defined on the basis of the distance to the stream compared to the total length of the hillslope from the distance to the ridge plus the distance to the stream. However, to simplify the slope of each measured SDtB point was derived utilizing the raster slope map in GIS in order to build the MLR model.

\section{Plan and Profile Curvature}

Plan curvature can be defined as the curvature of the terrain in a horizontal direction and used to differentiate between ridges and valleys. It can be also described as the curvature of the hypothetical contour line that passes through a specific cell. ArcGIS notification was adopted for the plan curvature as positive for cells with concave contours and negative for cells with convex contours (Fig. 4). Furthermore, the profile curvature is the curvature of the surface towards the direction of steep slopes (i. e. towards the vertical plan in the flow direction). The profile curvature affects the surface water flow velocity and influences erosion and soil deposition. Similar to the slope profiles, the point values of plan and profile curvature for all the measured SDtB points in GIS were extracted. 


\section{Compound Terrain Index}

The Compound Terrain Index (CTI) also known as Topographic Wetness Index (TWI) is a steady state wetness index, that quantify the topographic control on hydrological processes, is a function of both the slope and the upstream contributing area per unit width orthogonal to the flow direction (Qin et al., 2011; Sørensen et al., 2006). This index was used because it has been proven to be highly correlated with several soil attributes such as horizon depth, silt percentage, organic matter content and phosphorus (Moore et al., 1993). The implementation of CTI can be shown as (Eq. 1):

$$
C T I=\ln \left(\frac{A s}{\tan \beta}\right)
$$

where As is the specific catchment area expressed as $\mathrm{m}^{2}$ per unit width orthogonal to the flow direction, and $\beta$ is the slope angle expressed in radians (Gessler et al., 1995). ArcGIS spatial analyst tool for which D8 algorithm to calculate flow direction and contributing areas was used. In order to generate CTI, raster date sets of contributing area, flow direction were used to generate the CTI of the watershed. The CTI values (Fig. 5) generated from $20 \mathrm{~m}$ DEM satisfactorily represented the topo-sequence of terrain (e.g. higher values representing drainage depressions; lower values representing the hill crests, ridges and plateaus) (Ma et al., 2010; Qin et al., 2011; Sørensen et al., 2006).

\section{Land use/land cover (LULC)}

Since human intervention is extremely high in the watershed as mentioned in the earlier section, the use of land use/land cover attributes was important to better understand the SDtB. For this reason, the Landsat TM image (LPSO, 2008) of June 2015 and RapidEye of May 2014 was classified implementing supervised classification technique in GIS. The classified LULC map of the watershed is presented in Fig. 6.

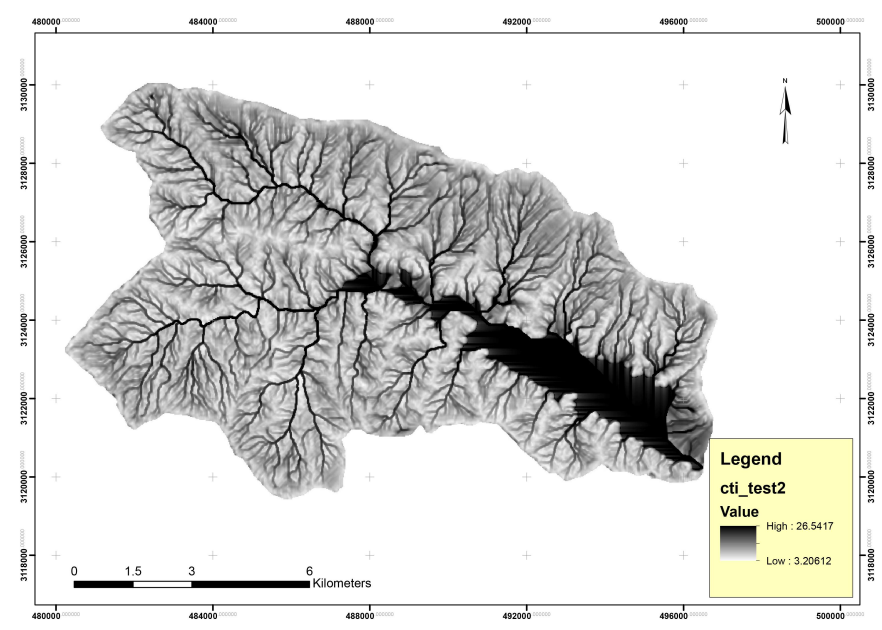

Fig. 5: View of Topographic Compound Index of Phewa watershed
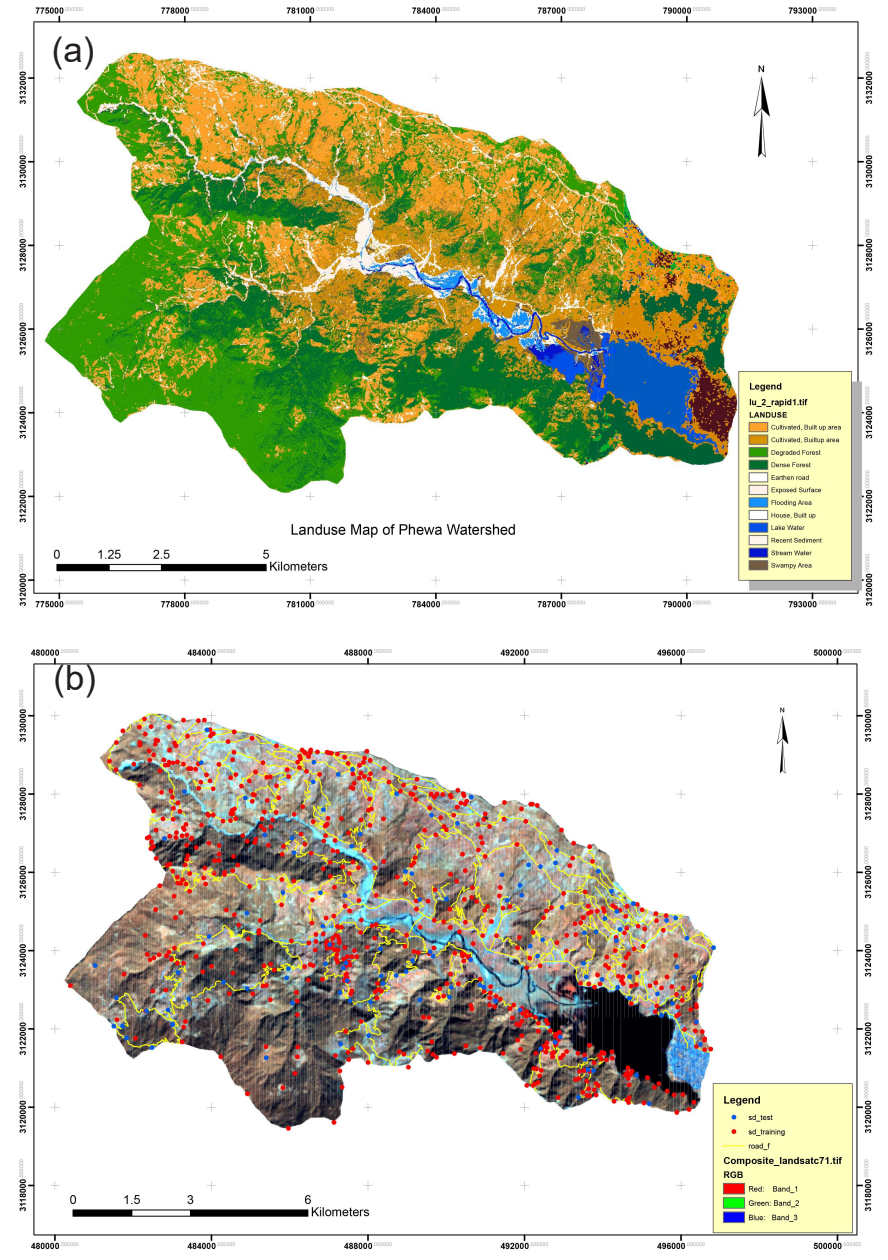

Fig. 6: (a) LULC and (b) point measurement over laid on Landsat image indicating testing (in blue points) and training (in red points) data and rural roads (in yellow lines)

A thematic map of LULC was then compared by a higher resolution Rapid-Eye image of May 2014. Aerial photographs and LULC maps were used to select training sites where the field observed land cover types (road, rocky outcrop and bare area; grasses; mixed grasses and shrubs; shrubs riparian, forests, cultivated land and water body) were identified and assigned a LULC code (e. g. 1 for road, 2 for cultivated, 3 for forest, etc). The raster calculator in ArcGIS was then implemented to extract the LULC attributes in the form of number that represents the LULC for all the measured SDtB points.

\section{Statistical Analysis}

\section{Normalization}

Box-Cox transformations (Sakia, 1992) were used to transform the measured SDtB and each explanatory variable so that their distribution was near normal (Eq. 2):

$$
t(x)=\frac{\left(x^{\lambda}-1\right)}{\lambda}
$$


where, $\mathrm{t}(\mathrm{x})$ denotes the transformation of variable $\mathrm{x}$ where transformation parameter $\lambda$. The latter was selected to maximize the Shapiro-Wilks normality test W statistic as in Tesfa et al. (2009) implemented in R (R Development Core Team, 2007; Shapiro and Wilk, 1965). Normalized variables were used in this paper for all the statistical modeling.

\section{Model}

Two types of prediction models were compared to predict the SDtB: 1) simple kriging (SK) and 2) multiple linear regressions (MLR) implemented in R (Pebesma, 2004) using above mentioned explanatory variables. SK is one of the simplest geo-statistical approaches to be applied to predict the value of unknown/unvisited locations. This technique utilizes the best fit variogram model of the training data set and the estimate relies on point observations (Hengl, 2007) and the model is as below (Eq. 3):

$$
z\left(s_{o}\right)=\sum_{i=1}^{n} \lambda_{i} z\left(s_{o}\right)
$$

where, $z\left(s_{0}\right)$ is the predicted value of the target variable (i. e. SDtB) at an unvisited location, $\mathrm{s}_{\mathrm{o}}$ gives its map coordinates,
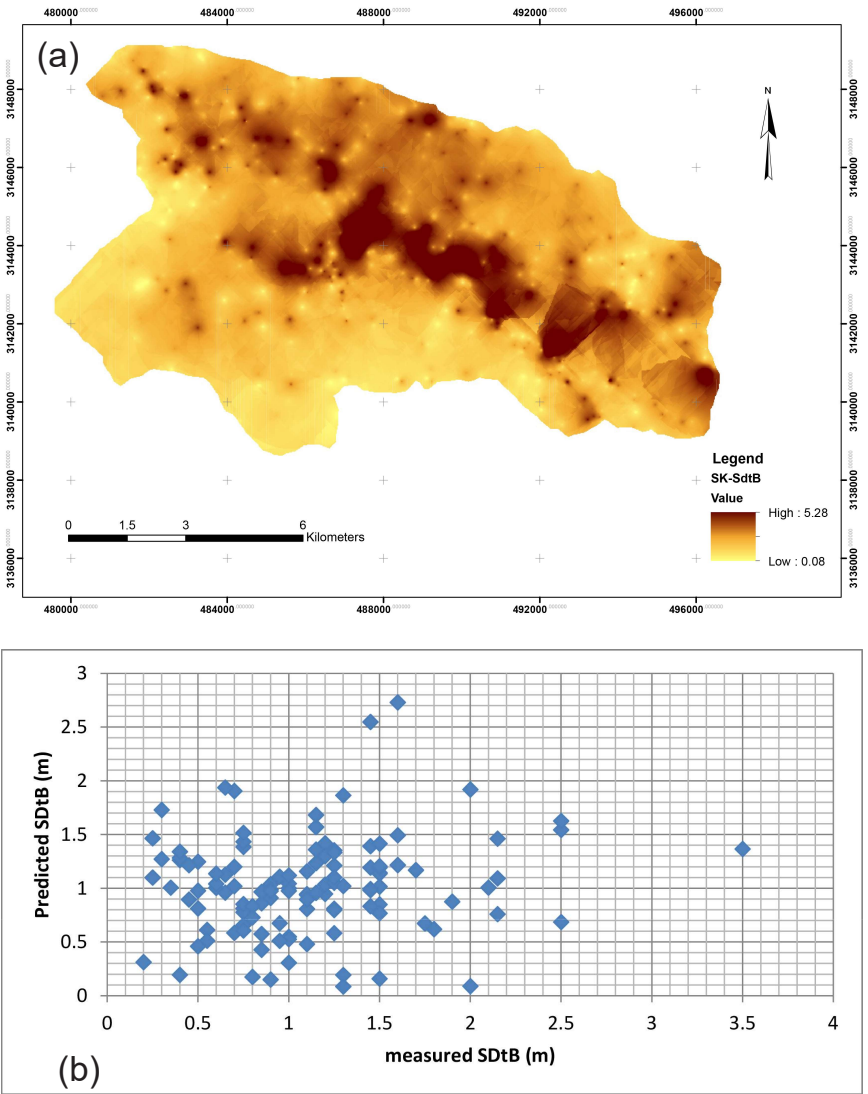

Fig. 7: (a) SK predicted SDtB map and (b) scatter plot of measured verses predicted SDtB. There is no clear trend. $\lambda_{\mathrm{i}}$ is the weights chosen such that the prediction error variance is minimized.

The SK estimates the SDtB values at unsampled locations by a weighted average of nearby samples. The correlations among neighboring values are modeled as a function of the geographic distance between the points across the study area, defined by a variogram (Miller et al., 2007).

MLR attempts to model the relationship between two or more explanatory variables (e. g. slope, CTI, etc) to that of response variable (i. e. SDtB) by fitting a linear equation to the observed data set. Every value of the independent variable $\mathrm{x}$ is associated with a value of the dependent variable $y$. The population regression line for $\mathrm{p}$ explanatory variables $\mathrm{x}_{1}, \mathrm{x}_{2}, \ldots . . \mathrm{x}_{\mathrm{p}}$ is defined to be:

$$
\mu_{y}=\beta_{0}+\beta_{1}\left(x_{1}\right)+\beta_{2}\left(x_{2}\right)+\ldots \ldots . . \beta_{p}\left(x_{p}\right)
$$

where $\mu_{\mathrm{y}}$ is the mean of the observations, which is SDtB. This line describes how the mean of response $\mu_{\mathrm{y}}$ changes with the explanatory variables. The observed values of $y$ vary around their means $\mu_{\mathrm{y}}$ and are assumed to have the same standard deviation $\sigma$. The fitted values $b_{0}, b_{1}, \ldots . . b_{p}$ estimate the parameters $\beta_{0}, \beta_{1}, \beta_{2} \ldots \ldots \beta_{\mathrm{p}}$ of the population regression line.
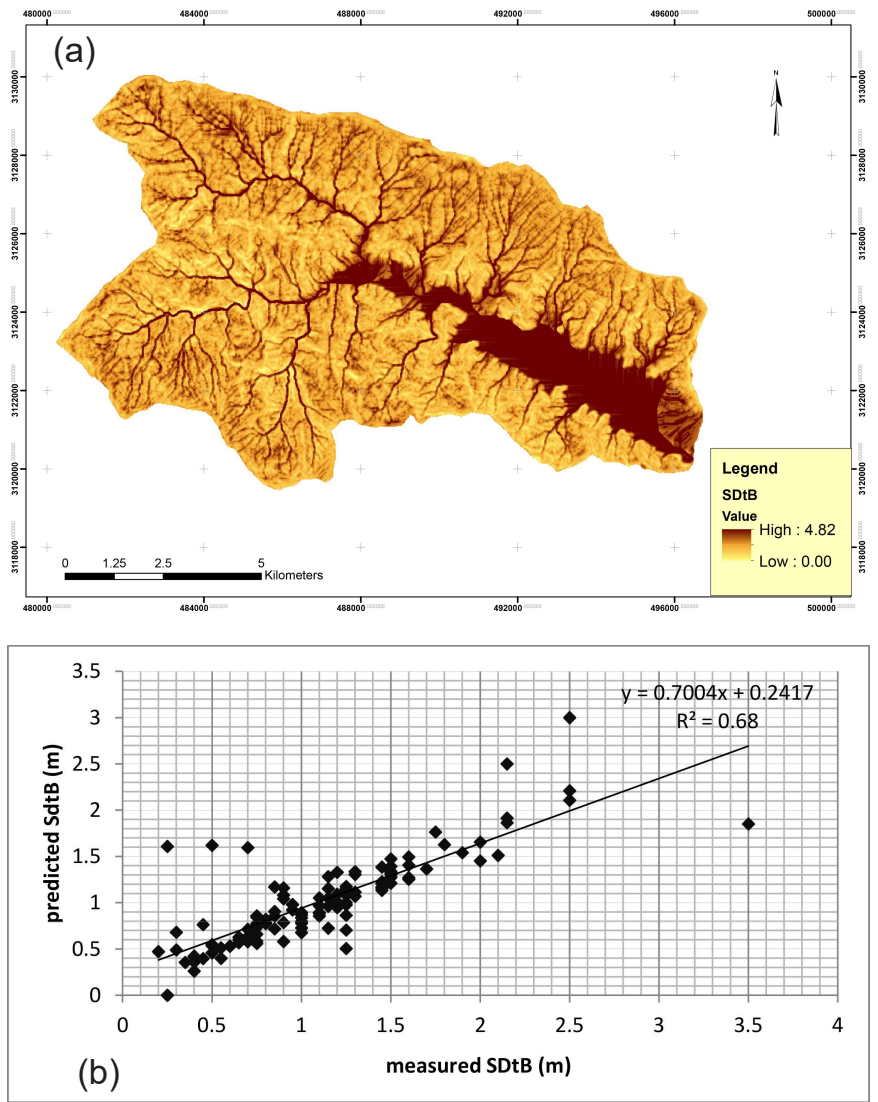

Fig. 8: (la) MLR predicted SDtB map and (b) scatter plot of measured verses predicted SDtB 


\section{Model Evaluation}

To evaluate the model results, the 865 data points were randomly split into two parts, designated as the training (80\%) and testing (20\%) sets as illustrated in the figure above (Fig. 6). Both SK and MLR models were implemented, using the training data set of 692 data points. The prediction error was computed for the testing data set according to Hastie (2001). The testing data set prediction error provided an out of sample estimate appropriate for trading off variance due to complexity with bias due to too few explanatory variables (see, e.g., Hastie, 2001). The results from this analysis allowed to select the explanatory variables and degree of model complexity as shown by Hastie (2001). This was done by utilizing the topographic variables derived in this study in predicting soil depth.

Once the explanatory variables and models with appropriate complexity had been selected, they were applied using the full training data set as input. Both SK and MLR models were used to predict soil depth for the entire watershed with the derived topographic and Land use variables. Then the testing data set was compared with the model SDtB values at testing locations using the Nash-Sutcliffe efficiency coefficient (EC) (Nash and Sutcliffe, 1970) and evaluated the coefficient of determination $\left(\mathrm{R}^{2}\right)$ (Moore et al., 2003):

$$
E C=\frac{\sum\left(X_{0}-\bar{X}_{0}\right)^{2}-\sum\left(X_{p}-X_{0}\right)^{2}}{\sum\left(X_{0}-\bar{X}_{0}\right)^{2}}
$$

where, $X_{0}$ is the observed (measured) value, is the mean of the observation and $X_{p}$ is the predicted value.

$$
R^{2}=\frac{1}{n-1} \sum\left(\frac{X_{0}-\bar{X}_{0}}{S_{x}}\right)\left(\frac{Y_{p}-\bar{Y}_{p}}{S_{y}}\right)
$$

where, $X_{0}$ and $\bar{X}_{0}$ are the observed and mean value of observation, $Y_{p}$ and $\bar{Y}_{p}$ are model predicted and mean value of the prediction, n, $S_{x}$ and $S_{y}$ are numbers of observation and standard deviation of $X_{0}$ and $Y_{p}$, respectively.

\section{RESULTS}

Fig. 7 presents the SK predicted SDtB map, where Efficiency Coefficient (E.C.) is negative (-0.46), coefficient of determination $\left(\mathrm{R}^{2}\right)$ is too low $(0.12)$ and SDtB map is coarse .

The MLR model was established utilizing the above discussed explanatory variables and the result was evaluated implementing E.C. and $\mathrm{R}^{2}$. Fig. 8 demonstrates the results of the MLR predicted SDtB map and the scatter plot of measured verses predicted SDtB. The test statistics indicated that the MLR predicted SDtB map was useful as it is statisticallysignificant where E.C and $\mathrm{R}^{2}$ were 0.93 and 0.68 , respectively.

\section{DISCUSSION}

Evaluation of SK predicted SDtB map showed the negative E.C. (-0.46) and very low $\mathrm{R}^{2}(0.12)$. In general E.C is varies from -8 to 1 . An efficiency coefficient of 1 (E.C=1) corresponds to a perfect match of the modeled SDtB to the measured data, whereas an efficiency coefficient of $0($ E.C $=0)$ indicates that the model predictions are as accurate as the mean of the observed data. The negative E.C (E.C. $<0)$ occurs when the observed mean is a better predictor than the model or in other words, when the residual variance is larger than the data variance (Goovaerts, 1999). For this reason, it was concluded that the SK predicted SDtB map was not useful that leads to use mean soil depth constant throughout the watershed. The evaluation also indicated that the simple geo-statistical approach was not a very convincing interpolation technique to estimate the SDtB in the complex geomorphological environment such as in the Phewa watershed.

SDtB is an important parameter for understanding the physical process of the landscape, which was observed to be difficult to predict in topographically complex environment, especially in a sensitive anthropogenic landscape such as Phewa watershed where high human intervention to terrace building, construction of rural roads and building new settlements. The highly variable SDtB in Phewa watershed has to be better understood to model the slope stability, sub-surface water balance, soil erosion and ecosystem services. Since the SK technique was not able to predict the SDtB as required, the explanatory variables (slope, plan and profile curvature, CTI and Land use) chosen to predict the soil depth implementing MLR according to Devkota et al. (2008) and Tesfa et al. (2009) were explored.

The MLR predicted SDtB map was found to be statistically significant and able to capture the complex geomorphological features of the watershed, where E.C was close to 1 (E.C. $=0.93)$ and the coefficient of determination $\left(R^{2}\right)$ was 0.68 . The chosen explanatory variables such as slope, plan and profile curvature, CTI and LULC were able to demonstrate reasonable relationship to the SDtB for the watershed. The relationship of the explanatory variables to $\mathrm{SDtB}$ is shown in the following equation (Eq. 7).

$$
\begin{aligned}
& \mathrm{SDtB}=0.302+0.176 . \mathrm{CTI}- \\
& 0.013 . \text { Slope }+0.103 . \text { Pro-curvature } \\
& +0.021 . \text { Pl-curvature }-0.007 . \text { LULC }
\end{aligned}
$$

The MLR model, however, was not very significant for the river valley and the lake surroundings, where the landform was flat and the SDtB was higher than that in the slope on the upper reaches. In the valley bottom the CTI was high, where deeper soil depth was observed. The CTI and profile curvature was positive to SDtB and other attributes such as slope, LULC and plan curvature were negative, meaning that higher the CTI and profile curvature, higher the SDtB. 
Upper reaches of the Phewa watershed was observed to be sensitive in terms of slope stability, where the fragile geology steep topography exist. In addition, the rural roads and human activities such as cultivation terraces and irrigation channels were more common in the upper and middle reaches of the watershed, making slopes more susceptible to failure. In other hand the valley bottom around the Phewa Lake is flat and wide where too much of incent sediment deposition as observed during the field survey. The MLR was not able to capture the deeper soil depth around the valley bottom. However, the model reasonably predicted the SDtB for the slopes and fragile to failure. The less steep areas and flat valley bottom are less prominent to failure and thus the MLR predicted SDtB map is useful to model the slope stability of the Phewa watershed.

\section{CONCLUSION}

The construction of unplanned rural roads in the Phewa watershed gave us easy access to large number of soil depth point measurements, which would otherwise very difficult to obtain. The measured SDtB points were used to build two models 1) Simple Kriging (SK) and 2) Multiple Linear Regression (MLR) respectively. A geo-statistical and nongeostatistical method used to predict the SDtB for the unsampled locations in the Phewa watershed. These approaches were adopted to see how well the simple geo-statistical approach demonstrates the SDtB over the MLR in the complex topography where anthropogenic activity is elevated as in Phewa Lake watershed in Panchase region of Nepal.

The SK was not suitable for predicting the SDtB in the topographically complex landscape of Phewa watershed as the test statistics (e. g. $\mathrm{R}^{2}=12 \%$ and $\mathrm{EC}=-0.46$ ) indicated that the model was insignificant. Thus MLR was examined, and was found to be statistically significant (e. g. $\mathrm{R}^{2}=68 \%$ and $\mathrm{EC}=0.93$ ). The explanatory variables such as slope, plan and profile curvature, CTI and LULC were able to predict SDtB reasonably of the middle and upper reaches of Phewa watershed. The SDtB map statistically significant and thus can be used in analyzing the slope stability and wherever precise soil depth data is necessary such as modeling of sub-surface hydrology, vegetation growth, soil erosion that helps to understand the physical process within the watershed.

\section{ACKNOWLEDGEMENT}

This work is the part of the Ecosystem Protecting Infrastructures and Communities (EPIC), a research project funded by Ministry of Building, Environment and Nuclear Energy (BMU) of German Government and is also a part of $\mathrm{PhD}$ research of the author for which International Union for Conservation of Nature (IUCN) provided the research grant and coordinated by the University of Lausanne (UNIL) Switzerland. We would like to acknowledge IUCN in Gland, Switzerland and in Nepal for providing the opportunity of this research to the Institute of Engineering (IoE), Department of Civil engineering of the Tribhuvan University, Nepal. We
Predicting soil depth to bedrock in an anthropogenic landscape

acknowledge the experts at the Risk Group at UNIL, Institute of Earth Science, Lausanne for letting us to use RapidEye imagery and providing guidance during the research. Many thanks to the local people and development partner in the Kaski District for their guidance, feedback and support during the field survey and providing valuable information about the watershed.

\section{REFERENCES}

Devkota, S., Sekhar, L.K., and Jetten, V.G. 2008, Prediction of oil depth using topographical variables for debris flow initiation modeling in the upper Tikovil River basin, Kerala, India. EGU 2008.

Devkota, S. and Adhikari, B.R., 2014, Development of Ecosystem based Sediment Control Techniques and Design of Siltation Dam to Protect Phewa Lake H arpan Khola Watershed Kaski. Kathmandu.

Gessler, P.E., Moore, I.D., McKenzie, N.J., and Ryan, P.J., 1995, Soil-landscape modelling and spatial prediction of soil attributes. Int. J. GIS, v. 9, pp.421-432.

Goovaerts, P., 1999, Geostatistics in soil science: State-of-theart and perspectives. Geoderma, v. 89, pp. 1-45. https://doi.org/10.1016/S0016-7061(98)00078-0

Goovaerts, P., 1997, Geostatistics for natural reources evaluation, Geostatistics for natural resources evaluation.

Hastie, R., 2001, Problems for judgment and decision making. Annu Rev Psychol, v. 52, pp. 653-683. https://doi.org/10.1146/annurev.psych.52.1.653

Heimsath, A.M., Chappell, J., Dietrich, W.E., Nishiizumi, K., and Finkel, R.C., 2000, Soil production on a retreating escarpment in southeastern Australia. Geology, vol. 28, pp. 787-790. https://doi.org/10.1130/00917613(2000)28<787:SPOARE $>2.0 . C O ; 2$

Heimsath, A.M. and Ehlers, T.A., 2005, Quantifying rates and timescales of geomorphic processes. Earth Surf. Process. Landforms, v. 30, pp. 917-921. https://doi.org/10.1002/esp.1253

Hengl, T., 2007. Practical guide to geostatistical mapping lof environmental variables.

Jaboyedoff, M., Michoud, C., Derron, M., Voumard, J., Leibundgut, G., Sudmeier-Rieux, K., Michoud, C., Nadim, F., and Leroi, E., 2016, Human-Induced Landslides: Toward the analysis of anthropogenic changes of the slope environment. Landslides Eng. Slopes. Exp. Theory Pract. pp. 217-232. https://doi.org/10.1201/b21520-20

Kobiyama, M. and Michel, G.P., 2015, Soil depth estimation and its spatial (and temporal) distribution, pp. 4-8.

Kuriakose, S.L., Devkota, S., Rossiter, D.G., and Jetten, V.G., 2009, Prediction of soil depth using environmental variables in an anthropogenic landscape, a case study in the Western 
Ghats of Kerala, India. Catena, v. 79, pp. 27-38. https://doi.org/10.1016/j.catena.2009.05.005

Leibundgut, G., Sudmeier-Rieux, K., Devkota, S., Jaboyedoff, M., Derron, M.-H., Penna, I., Nguyen, L., 2016. Rural earthen roads impact assessment in Phewa watershed, Western region, Nepal. Geoenvironmental Disasters, 3, 13. https://doi.org/10.1186/s40677-016-0047-8

LPSO, 2008. Landsat Project Science Office - Landsat 7 Science Data Users Handbook, Landsat Project Science Office.

Ma, J., Lin, G., Chen, J., and Yang, L., 2010, An improved topographic wetness index considering topographic position, in: 2010 18th International Conference on Geoinformatics, https://doi.org/10.1109/GEOINFORMATICS.2010.556 7607

Michel, G.P., 2016, Development of new equation to estimate the maximum soil depth by using the safety factor, pp. 1417-1421.

Miller, J., Franklin, J., and Aspinall, R., 2007, Incorporating spatial dependence in predictive vegetation models. Ecol. Modell. https://doi.org/10.1016/j.ecolmodel.2006.12.012

Moore, I.D., Gessler, P.E., Nielsen, G.A., A., and Petersen, G.A., 1993, Terrain attributes: estimation methods and scale effects, in: A.J. Jakeman, M.B.B. and M., McAleer (Eds.), Modelling Change in Environmental Systems. (London: Wiley, London, pp. 189-214.

Moore, I.D., Grayson, R.B., and Ladson, A. R., 1991, Digital Terrain Modeling?: A Review of Hydrological Geomorphological and Biological Applications. Hydrol. Process. v. 5, pp. 3-30. https://doi.org/DOI: 10.1002/hyp.3360050103

Moore, J.H., Thornton, T. A, and Ritchie, M.D., 2003, Basic statistics. Curr. Protoc. Hum. Genet. Appendix 3, Appendix 3M. https://doi.org/10.1002/0471142905.hga03ms37

Nash, J.E., and Sutcliffe, J. V, 1970, River Flow Forecasting Through Conceptual Models Part I-a Discussion of Principles*. J. Hydrol. v. 10, pp.282-290. https://doi.org/10.1016/0022-1694(70)90255-6

Pebesma, E.J., 2004, Multivariable geostatistics in S: the gstat package. Comput. Geosci., v. 30, pp. 683-691. https://doi.org/https://doi.org/10.1016/j.cageo.2004.03.012
Qin, C.Z., Zhu, A.X., Pei, T., Li, B.L., Scholten, T., Behrens, T., and Zhou, C.H., 2011, An approach to computing topographic wetness index based on maximum downslope gradient. Precis. Agric., v. 12, pp. 32-43. https://doi.org/10.1007/s 11119-009-9152-y

R Development Core Team, 2007. A language and environment for statistical computing, 2.5.0, No Title. R Found. Stat. Comput. Vienna.

Saco, P.M., Willgoose, G.R., and Hancock, G.R., 2006, Spatial organization of soil depths using a landform evolution model. J. Geophys. Res. Earth Surf. 111. https://doi.org/10.1029/2005JF000351

Sakia, R.M., 1992, The Box-Cox Transformation Technique: A Review. Stat., v. 41, 169p. https://doi.org/10.2307/2348250

Shapiro, S.S., and Wilk, M.B., 1965, An Analysis of Variance Test for Normality (Complete Samples). Biometrika, vol. 52, 591p. https://doi.org/10.2307/2333709

Sørensen, R., Zinko, and U., Seibert, J., 2006, On the calculation of the topographic wetness index: evaluation of different methods based on field observations. Hydrol. Earth Syst. Sci., vool. 10 , pp. 101-112. https://doi.org/10.5194/hess10-101-2006

Sudmeier-Rieux, K., Jaquet, S., Derron, M.H., Jaboyedoff, M., and Devkota, S., 2012, A case study of coping strategies and landslides in two villages of Central-Eastern Nepal. Appl. Geogr. vol. 32, pp. 680-690.

https://doi.org/10.1016/j.apgeog.2011.07.005

Tesfa, T.K., Tarboton, D.G., Chandler, D.G., and McNamara, J.P., 2009, Modeling soil depth from topographic and land cover attributes. Water Resour. Res. 45. https://doi.org/10.1029/2008WR007474

Tsai, C.C., Chen, Z.S., Duh, C.T., and Horng, F.W., 2001, Prediction of soil depth using a soil-landscape regression model: a case study on forest soils in southern Taiwan. Proc. Natl. Sci. Counc. Repub. China. B., v. 25, pp. 34-39.

ZIADAT, F.M., 2010, Prediction of Soil Depth from Digital Terrain Data by Integrating Statistical and Visual Approaches. Pedosphere, v. 20, pp. 361-367. https://doi.org/10.1016/S1002-0160(10)60025-2 